\title{
SOCIEDADE E ESTADO
}

\section{Euclides de Mesquita}

Docente Livre de Teoria Geral do Estado da Faculdade de Direito da Universidade do Parană.

O problema da transformação é da essência da vida social. Não se pode conceber a sociedade sem que esteja implícita a idéia de uma sucessiva evolução. E aí, poderemos sugerir que ocorre na vida social o mesmo que sucede ao indivíduo que, apesar de constantes transformações mantém, todavia, a sua unidade. Não significa, entretanto, essa unidade a ausência de modificações e mobilidade.

A vida social nada mais é que a continuidade de sucessivos momentos que, embora distintos uns dos outros, constituem uma rigorosa coesão.

É evidente, pois, que a sociedade política, não se pode furtar às mesmas leis de evolução que incide sôbre as organizações que servem de substratum concreto à organização dos Estados.

Assim, pois, estudar uma realidade estatal não supõe que se a considere como realidade independente e de conteúdo próprio e autônomo.

O Estado tem uma realidade, não independente, e que encontra suas raízes em determinados fatos sociais que o originam e o mantém.

Isto se deve a que uma determinada forma estatal só pode surgir quando uma totalidade vital a impõe. 
$\mathrm{E}$, assim, através de qualquer forma política, por transcendental que seja no seu conjunto, encontra-se um cosmos social.

O Estado, no entanto, deve ser considerado como uma individualidade concretamente fixada em suas motivações reais: a individualização das fôrças estatais consiste em sua redução ao marco histórico que, por seu nascimento, lhe corresponde.

Decorre dessa premissa que, para compreender uma específica realidade estatal, teremos de relacioná-la com o complexo histórico-sociológico, que lhe determinou a origem e lhe serve de base.

Cada uma das formas políticas que se sucedem através da história: Polis, na Grécia; Civitas e Império, em Roma; Land, na Idade Média; Estado, nos tempos modernos, - é produto de um conjunto de fatores que correspondem a uma determinada época histórica. - É certo, pois, que uma organização política é o resultado dessas circunstâncias que marcam uma fase histórica: analisá-la sob êste aspecto, individualisá-la, situá-la nas fronteiras de seu tempo, é dar o alcance que merece o estudo dessas organizações.

E já o próprio Marx, e também Engels, in Archives, n. 1, pág. 206, citado por Hermann Heller, em sua obra Teoria do Estado (1), declaravam: - "A organização social e o Estado nascem, em forma ininterrupta, dos processos vitais de determinados indivíduos, porém, não como imagina a representação própria e alheia, mas, tal como realmente elas são, isto é, tal como obram e produzem materialmente, dentro de determinados limites e sob determinadas influências independentes de seu arbítrio. "Sem aceitar interamente o conceito acima citado, comprova êle no entanto, que tôdas as ideologias se conjugam para acentuar a base social da organização política: 0 Estado.

(1) Alfredo Povina - Cursos de Sociologia, Ediciones Assardri-Cordoba. 
É, pois, certo e evidente, que o Estado é uma expressão da realidade social. Forma parte, assim, da organização social e nada mais é que uma instituição social, de caráter próprio inconfundível, com imensas projeções sociais, e confere tona. lidades especiais ao grupo sôbre o qual incide.

Poderíamos dizer, sociológicamente, que é uma superestrutura que mediante a ordenação jurídica do instinto de poderío, satisfaz as funções políticas da vida do grupo, na definição de Alfredo Povina (2).

Todavia, é bom acentuar que a Sociedade e o Estado são entidades distintas: O Estado emana da Sociedade que é anterior e não se confunde com ela.

Hobbes, Rousseau e Locke, ao afirmar a idéia de pacto ou contrato na formação da Sociedade política, estão revelando a diferença fundamental entre o corpo social e o político.

Uma vez que se aceitava a distinção entre Sociedade e Estado era necessário justificar a emanação que o Estado obtinha da sociedade.

Tal missão caberia às idéias de soberania popular e representação política.

$\mathrm{Na}$ formulação da idéia da soberania popular confluem as mais variadas e antitéticas correntes de pensamento. De um lado, os teóricos da contra-reforma desejando debilitar o Estado laico e agressivo e fortalecer a Igreja, pretendem dotar o povo do princípio de soberania. De outro, Hobbes, teórico do Estado Absoluto secularizado afirma haver o povo perdido voluntàriamente a soberania ao praticar o "Direito de Cessão" em favor do monarca, em benefício da ordem, Rousseau, atacando a Hobbes a quem acusa de logo conceder um direito ao povo para arrebatá-lo em seguida, é quem elabora fundamentalmente a noção de soberania popular; a soberania reside originária e essencialmente no povo, sendo imprescritível e ina-

(2) Herman Heller - Teoria del Estado - Fondo de Cultura Econômica - México. 
lienável. Mesmo por vontade própria, não pode o povo alienar sua soberania. Rousseau é tão cioso dessa idéia, que repele totalmente a idéia de representação política que Hobbes havia rudimentarmente elaborado, construindo através de sua teoria da "vontade geral" um tipo de democracia direta: uma espécie de laço de identidade entre povo e govêrno,

Idéia de representação, todavia, era um lógico corolário do princípio de soberania popular, no mesmo conceito do próprio Rousseau, como o demonstra o fato de que Sieyes, seu continuador, foi o grande teórico da idéia de representação.

Na gestão do princípio de representação política tem grande influência a idéia do mandato elaborada pelo Direito Privado; Hobbes fudamenta-o sôbre bases jusprivativas e os primeiros representantes políticos eram clássicos mandatários que, ingenuamente, levavam em caderno as concretas instruções dadas pelo mandante: o povo que os elegia.

Todavia, deve-se compreender que a representação política obedece a razões específicas, separadas por fundos abismos, das razões que motivam o mandato.

Com efeito, sendo o povo soberano, o exercício de sua soberania resultava, por sua própria natureza sociológica de povo, impossível de verificar-se com a frequência que as características da soberania requer. Então, para fazer perceptiível e atualizar sua vontade soberana, necessitava recorrer-se a um ser de presença pública manifesta e de vontade atualizada a todo momento: sua representação. É nesta forma depurada, como o conceito de representação política informa ao Estado Moderno.

Na Declaração de Direitos do Cidadão, de 1.789 e na Constituição Francesa de 1.791 , os conceitos de soberania e de representação política são alí consignados, pode-se dizer, como elementos insubstituíveis do Estado Moderno. Daí em diante, - Estado terá sempre em conta que o soberano é o povo e que sua legitimação como organismo estatal, depende de que seja êle representativo da soberania popular, ou da Sociedade organizada em quadros políticos. 
o Estado é, assim, uma instituição social co-natural com a Sociedade e desta dependente como organismo social para sua objetivação própria e específica.

Durkheim (3) afirmou que os oindivíduos encontram as instituições formadas e não podem codificá-las. Nasceram, diz êle, por obra dos mesmos homens e são por isso um produto novo. Uma instituição, define Durkheim, é um conjunto de crençase formas de conduta instituidas pela coletividade. As instituições formam a parte fixa, cristalizada, não movível, nem transformável pela vontade dos indivíduos as quais têm um poder coercitivo sôbre os homens mesmos. São êsses, entretanto, os dois grandes aspectos que integram uma só e única realidade: o processo de interação social com os seus dois momentos essenciais: o processo vivo da interação social e o resultado fiscalizado dessa interação: as instituições sociais, d€ que o Estado é, na opinião de Le Fur, o fato mais relevante de todos (4).

É evidente que a idéia de Estado, como a síntese da convivência humana, não se possa separar do conceito de sociedade.

O viver coletivo ou em sociedade, foi sempre a marca do homem na terra. Êsse querer viver coletivo constitui sucessivamente os clans, as tribus, os povos, as cidades, os impérios, as nações. Cada um dêsses estágios revela um conjunto de regras, costumeiras ou codificadas.

No direito dos povos civilizados, deu-se então o nome de Estado, a êste sistema de formas institucionais, pelas quais se traduz a vontade coletiva. O Estado é, então, uma representação coletiva, definida, específica e que é a alma das instituições políticas. E porque o querer viver coletivo existe por si mesmo, diz-se que o Estado é autônomo. E porque êle se eleva

(3) Durkheim - De la division du travail social-Paris, 1893.

(4) Louis Le Fur - Races. Nationalités Etats - Librairie du Re. cueil Sirey, 1920. 
acima dos indivíduos e suas expressões tomam caráter imperativo diz-se que o Estado é soberano.

Todavia, e é certo, como já o dissemos acima, a Constituição do Estado replete a estrutura social. A noção de sociecade é, portanto fundamental, pois, na observação de Von Stein (5), a sociedade constitui a matéria prima de que se formou o Estado.

Por isso é que Vareilles Sommiéres (6), considera o Estado ou Nação, co a forma que reveste a sociedade civil como unidade autônoma e independente.

Todavia, é de assinalar que, embora seja o Estado o produto de uma evolução natural, resultado de transformações sociais, em que teve maior influência o próprio desenvolvimento da sociedade, com tôdas as suas lutas, guerras e desentendimentos, não se pode excluir de tudo isto uma grande parte de vontade e iniciativa particular e indiretamente, como acentúa Blunstchli (7), pela atividade do homem, utilizando-se dos meios que lhe fornece a natureza. Diretamente, pelas manifestações sucessivas da vontade humana, na organização da estrutura do Estado e no congraçamento de seus semelhantes em tôrno de ideais e princípios comuns,

Daí decorre, de consequência, as numerosas modalidades de Eistado, dêsde os tempos primitivos até hoje, diferenciadas pela estrutura interna e formas de govêrno.

É, assim, profunda e indestacável a noção de sociedade da de Estado. Aquela serve de substratum estrutural e formal a êste que, para exteriorizar-se na sua autoridade e autonomia, repousa seus fundamentos na organização social.

Entre os fatos sociais que se produzem no seio da Sociedade, destacam-se os jurídicos e os políticos, ao lado de outros menos complexos. Mas, assim considerando, se o direito é um fa-

(5) Von Stein - La Scenza della Publica amministrazione.

(6) Vareilles Sommiéres - Les principes Fundamentaux du droit.

(7) Bluntschelt - Theorie Generale de l'Etat. 
to social, será lícito considerar o Estado, órgão de Direito, idêntico à Sociedade, organismo onde se produzem outros fenômerıos sociais: os econômicos, os religiosos, os artísticos, os científicos os morais?

É de advertir que Sociedade e Estado, no rigor da linguagem sociológica, são expressões equipolentes, são conceitos idênticos. Tudo depende, naturalmente, da idéia que formamos de Sociedade e Estado. A Sociedade, ordinàriamente, anda ligada ao Estado que a organiza em nação; mas, não sòmente a idéia de Sociedade é mais extensa que a de Estado, como ainda $\dot{e}$ diferente. É mais extensa porque compreende agrupamentos humanos a que não se a liga o conceito de Estado: a sociedade das Nações. São exemplos de agrupamentos humanos a que, evidentemente, não convém a denominação de Estado.

É diferente porque a idéia fundamental de Sociedade é a de agrupamento para a realização de fins comuns, de cooperação dos associados; e a idéia fundamental de Estado é a de organização da autoridade para manter o equilíbrio dos interễsses pela aplicação do direito. É êsse aliás o ponto de vista de Ihering (8), que tenho por verdadeiro: o Estado é a organização das fôrças coativas da sociedade, e essa coação se opera no sentido da conservação e do desenvolvimento da sociedade.

Contra êsse modo de ser não procede a objeção de que não havendo Estado sem Sociedade, as duas palavras não traduzem o mesmo conceito: porque se o Estado organiza política e jurìdicamente a sociedade não pode existir sem ela: mas, por isso que a organização presupõe outros elementos a que dà organização. As indústrias, o comércio, as artes, a ciência, a religião são formas de atividade social, mas não são formas de atividade do Estado, cuja função é assegurar-lhes a vida e a expansão, segundo as normas criadas pelo interêsse geral.

(8). Von Ihering - A luta pelo direito. 
É por isso, por essa supervisão às normas do viver social que não se confunde com a própria existência do Estado que Legaz y Lacambra (9), ensina que o Estado é uma realidade existencial co-natural ao homem e, em um certo sentido, significa o paradigma de tôdas as formas de união social. O Estado constitui uma comunidade perfeita, segundo a doutrina exposta por Suarez (10).

Dêsde o momento em que o Estado é uma instituição co-natural ao homem, possui um valor próprio, ético e não meramente utilitário. Todavia, é preciso assinalar que é de se recusar a doutrina hegeliana que vê no Estado a culminação da éticidade, a suprema realização da idéia moral. A doutrina do Estado ético padece do vício fundamental de identificar a realidade existencial do Estado com os valores concretos que encarna, com o ideal de um Estado em que culminam os mais altos valores éticos e espirituais.

Uma semelhante doutrina significa a negação absoluta da liberdade radical da existência e leva a absorver tôdas as dimensões da pessoa em uma organização cuja justificação racional, dogmàticamente se supõe.

Mas a liberdade humana transcede necessàriamente, ao Estado e a garantia de sua salvação no que tem de autêntica é profunda, está em sua eterna possibilidade de dizer "não" em frente ao fato concreto de um Estado que não atúa ou não encarna os postulados da consciência moral da humanidade.

Todavia, é certo que o sentido do Estado não se define nem pelos valores religiosos, nem pelos valores éticos, nem pelos valores concretos da culutra que possa realizar, mas pelo valor do Direito. O Estado se define pelo Direito, não porque se confunda e se identifique com êle, mas por ser a a comunidade jurídica por excelência, pois, não há Estado sem Direito, ainda que haja Direito sem Estado.

(9) Legaz y Lacambra - Theoria Generale del Derecho,

(10) Recaens - La Philosophia jurídica del P. Suarez. 
De qualquer maneira é certo que o Estado assume a evidência de um fato social dos mais transcedentes na vida do agrupamento humano, e nem se pode traçar, de modo, o quadro de seu aparecimento, de tal modo se processa uma profunda simbiose entre êle e a Sociedade. 